\title{
The Role of Demography in the Distribution of Advertising Animation Products via Chinese Communes (An analytical study)
}

\author{
Dina Ali Mohamed El-Besomey
}

Assistant teacher of advertisement\& print\& publish department, Applied art faculty , Benha University, Egypt.

\section{KEY WORDS:}

Animation-Advertisement-Demography-Animation Products-Chinese Communes-Multimedia- Computer Graphic \&Animation Software

\begin{abstract}
:
This study focuses on the contemporary Chinese animation industry, especially The Role of Demography in the Distribution of Advertising Animation Products via the Experience of Chinese Communes (An analytical study).as it studies the concepts of Demography ,Advertising Animation Products, Chinese Communes, and the impact of them on the contemporary Chinese industry. Also on another hand explain that many of the animation companies suffer from such as the production reduction, the expensive costs ,to produce animation films with high quality ,so Chinese and American companies concentered with the post- production stage to profit, and that what we will study in this research
\end{abstract}

\section{INTRODUCTION:}

This research Studies the Role of Demography in the Distribution of Advertising Animation Products via the Experience of Chinese Communes. Also this research studies the contemporary Chinese animation industry. The roadmap of my two years research statement is accessible to a relatively broad audience of academics. It will provide a clear and succinct picture of my short and long term programmatic research goals. There is the summary for the present purposes of my two year research goals and strategies, incorporating the following components:

The idea of this research depends on what many of the animation companies suffer from such as the production reduction, the expensive costs, to produce animation films with high quality, which requested particular composer \& script writer deal well with the ages introduced to her this animation ,also the quality of technology ,professional director, so there must be a solution to produce succeeding animation with its nationality, which children love it and grow up their thoughts \&sense, get them delighted, with positive ideas and experiments as the animation industry \& each other nationality industries needs to profit to go on their way .

\section{Research importance}

Because this research discusses The Role of Demography in the Distribution of Advertising Animation Products via the Experience of Chinese Communes production vs. the international market also the research describes the importance of post-production stage -this is disappearing Stage at the Chinese and American animation industry, and the results of saving job opportunities for international creative qualification designers, animators, Anime directors, and producers.

\section{Research Objectives}

-Recognized the Mechanisms of implementation 
\& the technology of Asian manga \&anime production via multimedia, like: the prints as journals, article magazine, cinema, TVs, web, mobile, all of that at china \& America.

- Utilize from the pioneer\& creative ideas of the American Animation production for developing the Chinese animation industry technical\& Produce via publishing\& marketing \&distribution locally and regionally vs. the international market. - Studding how the Dumping of the Chinese animation products will be increased the ten coming years, like: movies, series on dvd ,school tools, electronic games, toys the markets of Middle East, Arab World, European \& international market in this period and the necessity of Address it - Transferred technology, innovation and creativity between Egypt, china, and America will make us up-to-date with the latest innovations all over the world to get develop and progress ourselves. - studying the exchange of technological Experience and scientific Missions between all sides of
Egypt, japan, china, especially at the field of the technology of manga\& anime production and the reflection of them on the Egyptian animation industry to be up-to-date with the latest version of Asian computer graphic and animation, also with the recent events in Asian cinema, multimedia and animation industry.

\section{Research problem:}

The problem of Research determine in study the Similarities and the differences of Chinese and American post-production animation stage -, and how it's saving job opportunities for international creative qualification designers, animators, Anime directors, and producers.

\section{Research methodology: analytical Study}

\section{Research limits:}

- The place limits: china, and America

- The time limits :( from 1990 to 2019).

First: The people's communes illustration drawings

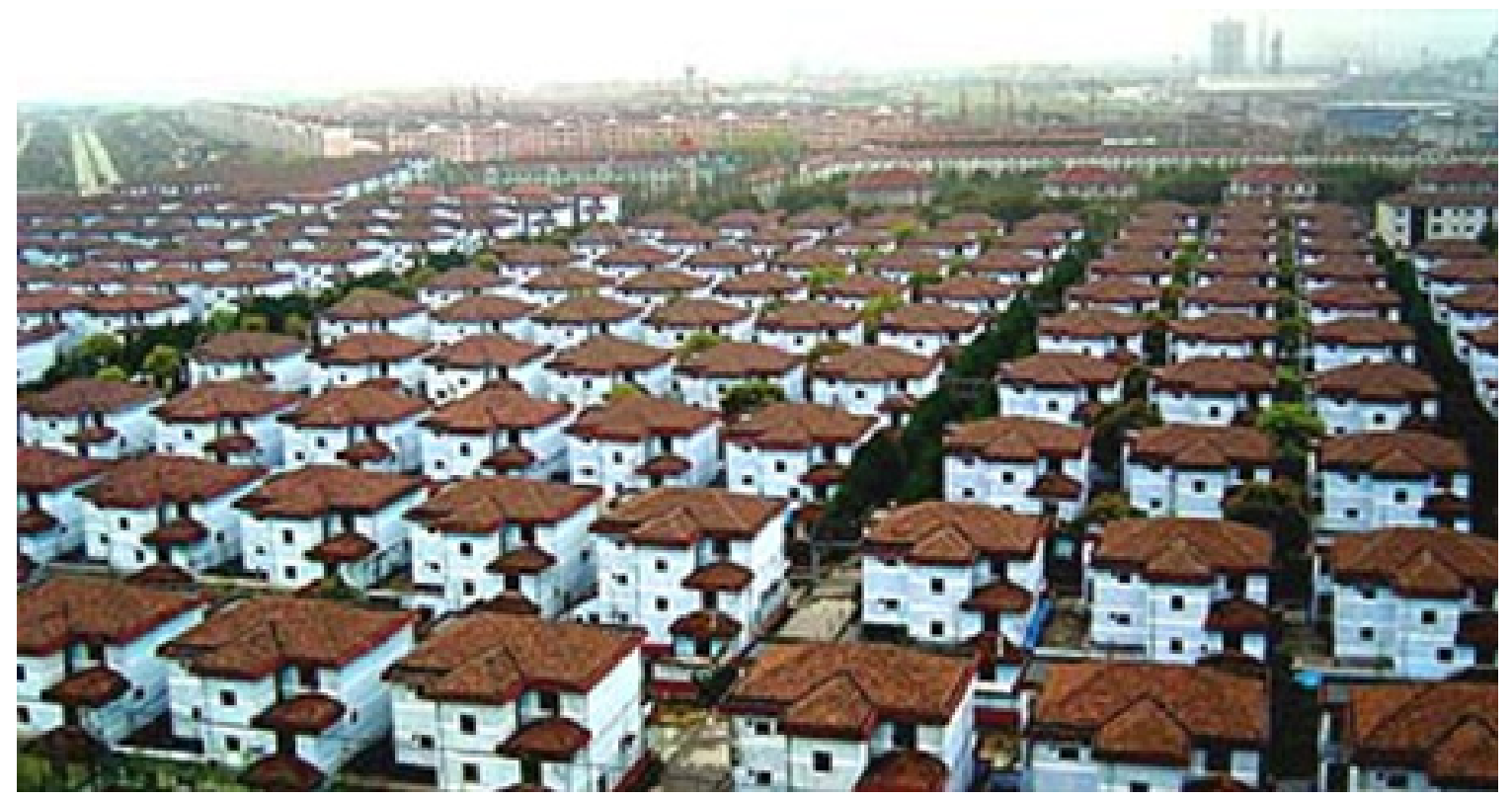

Figure (1) 


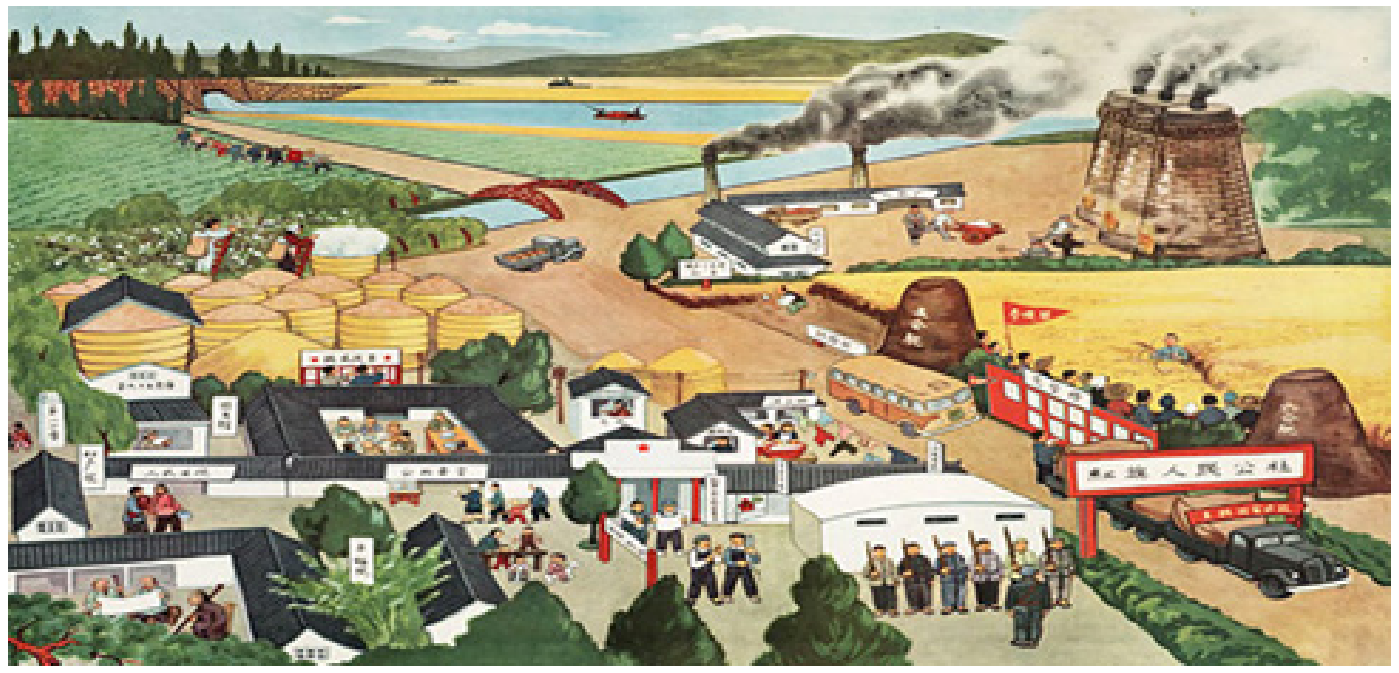

Figure (2) The people's communes are good Renmin gongshe hao, 1958Designer: Rui Guangting, Publisher: Shanghai educational publishing house, Size: 77.5x 108.5 cm. Call number: BG G1/959 (IISH collection)

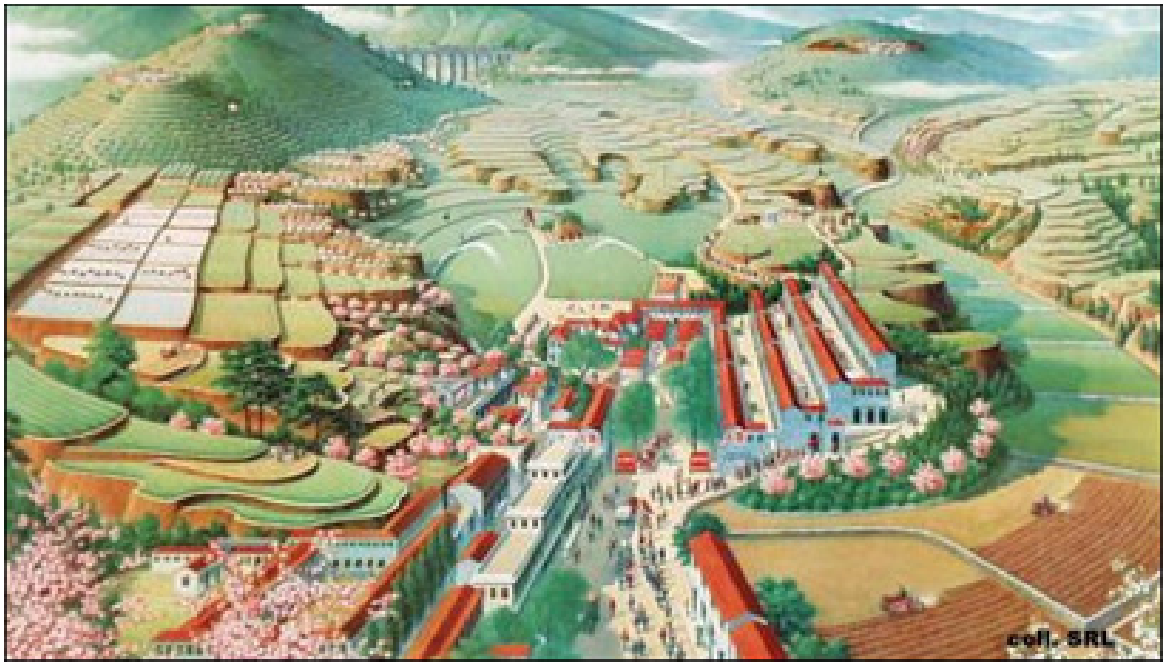

Figure (3)

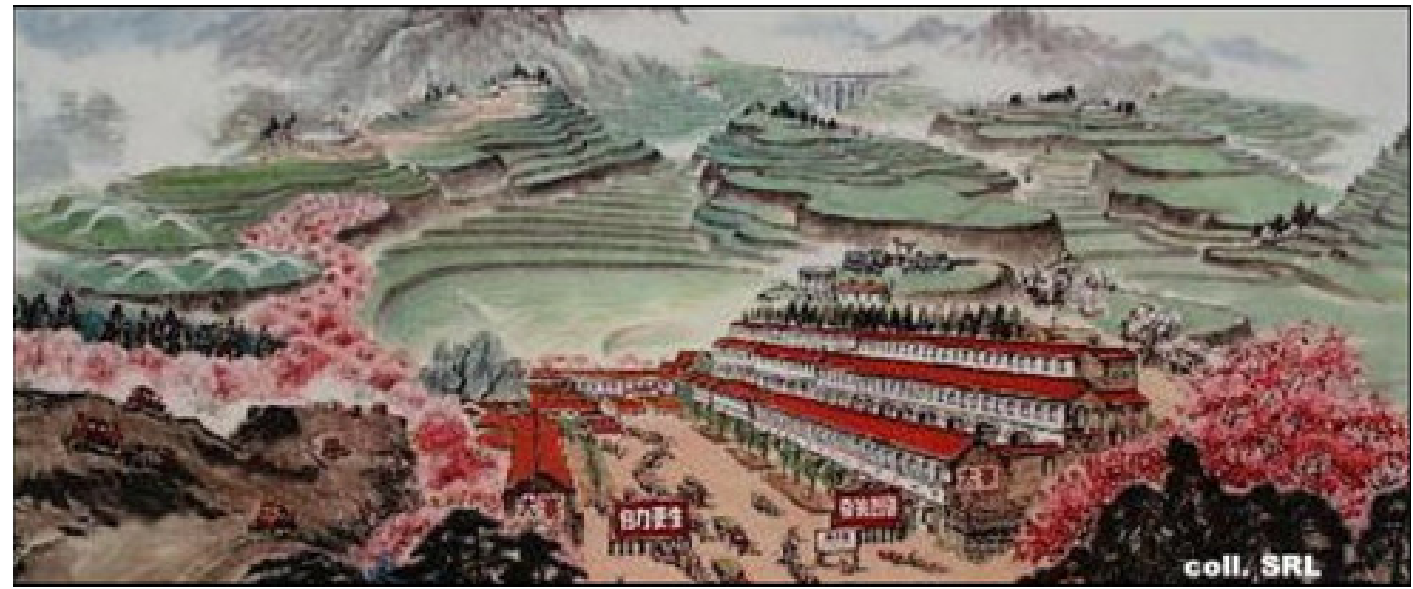

Figure (4) 
Second: The Products of the post-production stage of Chinese animation

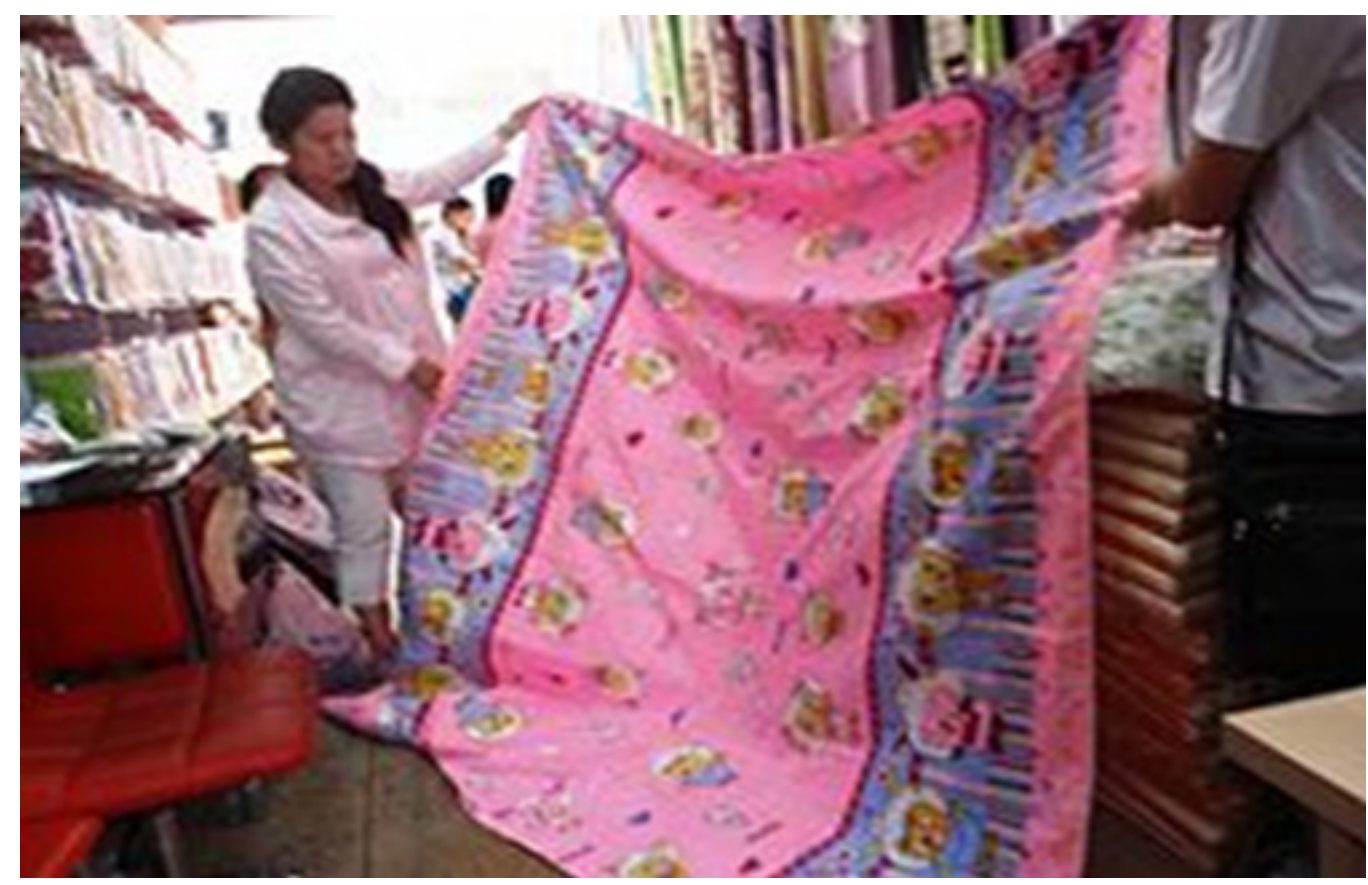

Figure (5) Products of the post-production stage Of the movie The Goat and the Great Witch

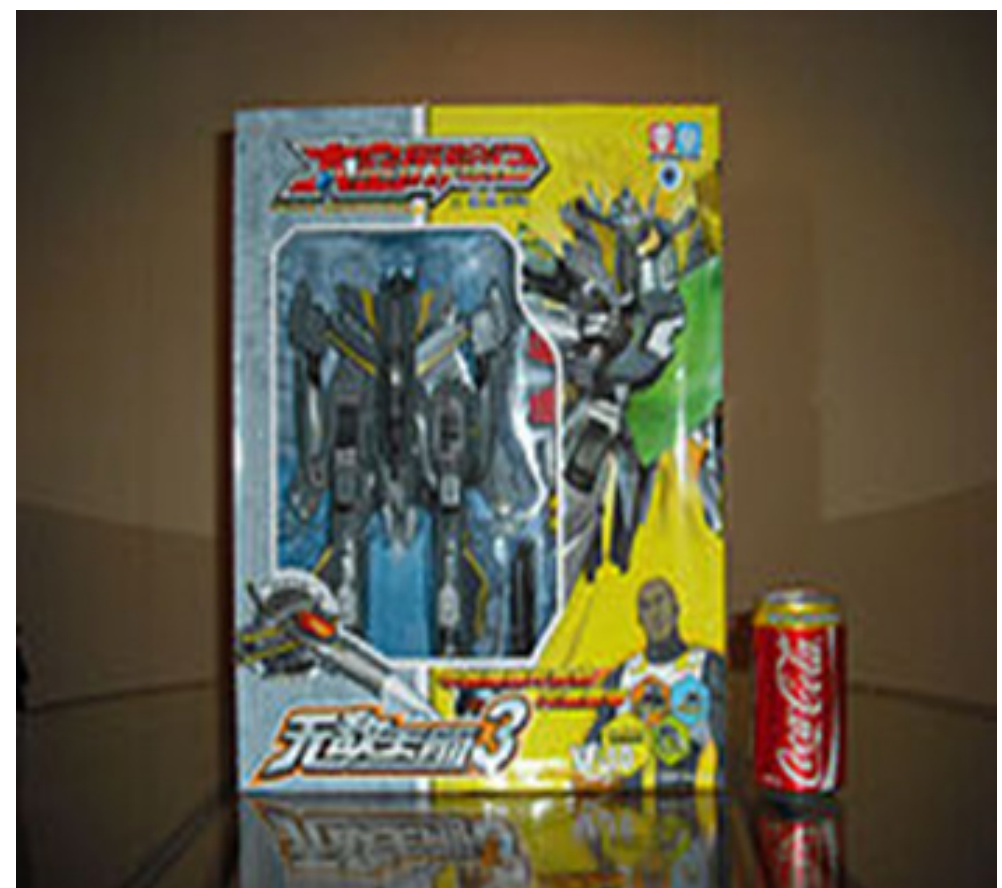

Figure (6) An animated product of "Astro Plan" 
Third: The Tools Used By Mangaka \& Animator to Draw Manga \&Anime Digitally

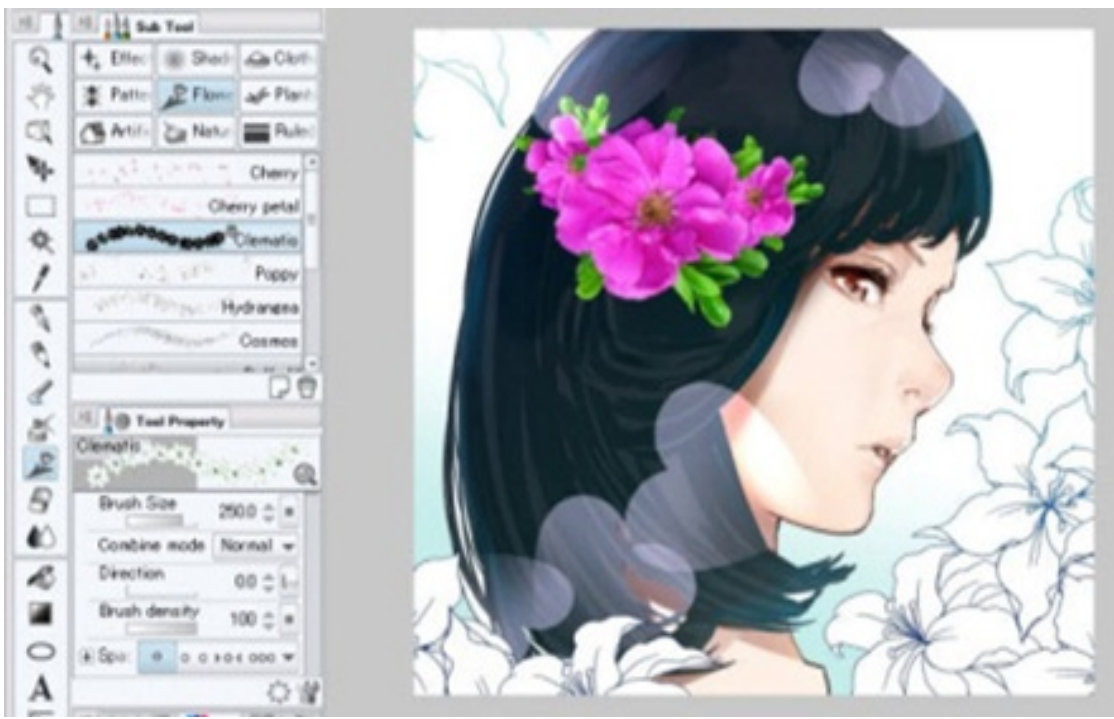

Figure (7) Clip Paint Studio PRO program
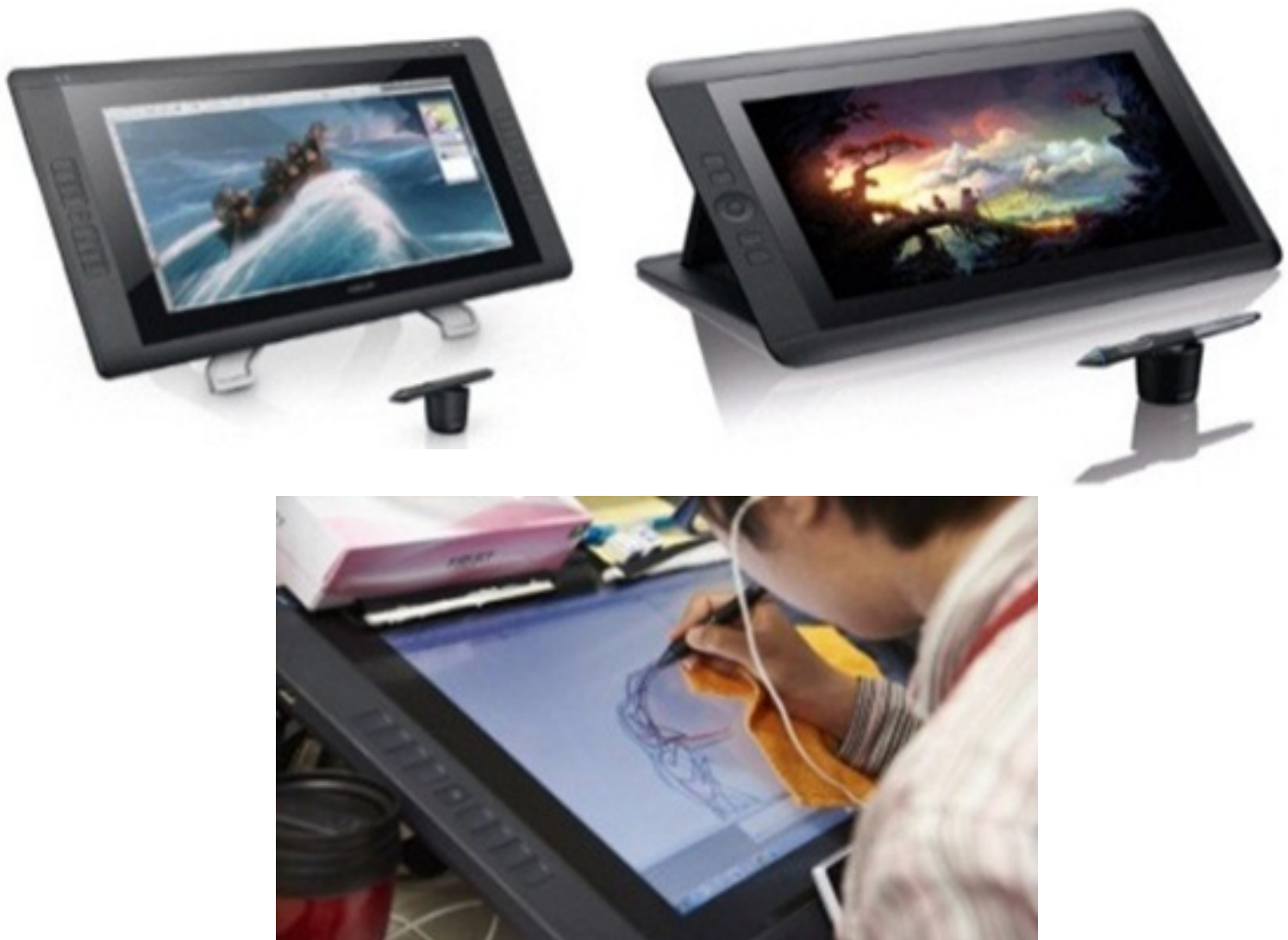

Figure (8) Cintiq 13HD Pen Digital Graphic Display Screen, Cintiq 22HD Pen Digital Graphic Display Screen, Bamboo Feel StylusDigital Graphic Display Screen 


\section{Materials and Methods}

There is the summary for the present purposes of many years' research goals and strategies, incorporating the following axes of the research plan:

\section{The main axes of the research plan:}

-The first axis: The impact of demographic planning on the Chinese animation industry

-The second axis: study the concept of the experience of Chinese communes on advertising animation products.

After my First Academic Degree: Fine Arts Bachelor(B.A)/Animation Department/Fine Arts Faculty, I Choose with my supervisor : Prof. Assistant .Dr. Aid Mohammed Abd El - Latif of My Master Degree subject to be about" The Chinese Animation Between National Identity And Industry". And after that I published many researches about Chinese animation in the contemporary china reality.

And I participate at many co- Chinese - Egyptian conferences/Helwan University

- The third axis: Study of samples of the experiences of Chinese communists in the distribution of advertising animation products

- The fourth axis: the development of artisanal industries related to advertising animation products

- Fifth axis: study the Chinese media (Chinese - Media) used to compete with the global animation industry (American - Media).

- Sixth axis: strategic marketing of the computer industry, graphics and animation in the Chinese media

- Seventh: The role of the Chinese state in the adoption of legislative and parliamentary decisions in support of the Chinese animation industry and attracting foreign investment to establish an information empire.

\section{Results and discussion}

(1) Transferred technology, innovation and creativity between Egypt, china, and America will make us upto-date with the latest innovations all over the world to get develop and progress ourselves.

(2) The exchange of technological Experience and scientific Missions will increase the coming twenty years between all sides of Egypt, japan, china, especially at the field of the technology of manga\& anime production.

(3) The impact of the technology of manga\& anime production will increase and reflect on the Egyptian animation industry.

(4) The Egyptian animation industry should be up-to- date with the latest version of Asian computer graphic and animation, also with the recent events in Asian cinema, multimedia and animation industry to develop the global industry.

\section{Conclusion}

Finally, this research ended by exploring the new in contemporary Chinese animation technologyand its stages. At the end the research's results \& recommendations, introducing experiments in which could be progressed this industry in china \& America.

\section{Results and discussion}

(5) Transferred technology, innovation and creativity between Egypt, china, and America will make us upto-date with the latest innovations all over the world to get develop and progress ourselves.

(6)The exchange of technological Experience and scientific Missions will increase the coming twenty years between all sides of Egypt, japan, china, especially at the field of the technology of manga\& anime production.

(7)The impact of the technology of manga\& anime production will increase and reflect on the Egyptian animation industry.

(8) The Egyptian animation industry should be up-todate with the latest version of Asian computer graphic and animation, also with the recent events in Asian cinema, multimedia and animation industry to develop the global industry.

\section{References}

\section{1-Arabic translation of a book}

Prenza „Kisy Ie(june2009)books not comics; publishing fields, globalization and Japanese manga in new york", chapter publishing research. New York: springer, new york25 (2): 101-117. ISSN 1053-8801.dui: 10.1007/s12109-009-9114 -2

\section{Unpublished doctoral dissertation}

(1)Heba Ibrahim zaki farag, manga \&anime of the war in Japan as expressional style, $\mathrm{PhD}$ a thesis dis publishing, graphic department, fine art faculty, Helwan University, 2013.

(2)Hartzheim, Bryan Hikari, Inside the Media Mix: Collective Creation in Contemporary Manga and Anime, unpublished Ph.D. thesis, Film and TV Department, University of California, Los Angeles, United States, ProQuest Dissertations Publishing, 2015. 3704581 .

(3) Jacobsen, Matthew, The wandering adolescent of contemporary Japanese anime and videogames, Queen Mary University of London (United Kingdom),ENGLAND, unpublished Ph.D. the- 
sis, ProQuest Dissertations Publishing, 2014. 10088506.

(4) Kim, Sahangsoon .Short-term project organizations for corporate entrepreneurship: Evidence from the Japanese animation industry (2000-2008), unpublished Ph.D. thesis, Business Administration Department,University of Southern California, United States ProQuest Dissertations Publishing, 2010. 3434447.

(5) Liu, Xueting, Perception Analysis for Manga and Anime Applications, unpublished Ph.D.

(6) thesis,Computer Science and Engineering Department ,The Chinese University of Hong Kong (Hong Kong), ProQuest Dissertations Publishing, 2014. 3707446.

(7) Lee, Laura .Cinema of the interval: Stop -motion animation and Japanese film aesthetics, unpublished Ph.D. thesis ,Cinema and Media Studies Department, The University of Chicago, Illinois -United States ,ProQuest Dissertations Publishing, 2010. 3419663.

\section{2- Unpublished master's thesis}

(1) Rahab Allah Ahmed Hany Abd Al Daim El-Nagar ,animation art in east Asian area ,decoration department, applied art faculty, Helwan university,2008.

(2) Guo, Fang .Institution influence of Chinese and Japanese animation and comic industry in different path, unpublished master thesis, Shanghai University (People's Republic of China), ProQuest Dissertations Publishing, 2010. 10389692.

(3) Gao, Jing Jing .The charm of i-go soul--study on Japanese comics and animation of i-go soul, unpublished master thesis, Central South University (People's Republic of China), ProQuest Dissertations Publishing, 2009. 10535018.

(4)Kwon, Jae-Woong. The development of digital cultural products in the age of globalization: Focusing on the Korean digitalized animation industry, Temple University, Pennsylvania- United States, ProQuest Dissertations Publishing, 2006. 3233444.

Liu, Cheng .Developing Chinese artistic elements in sci-fi animation environment design, Unpublished master thesis ,Peking University.

(5) (People's Republic of China), ProQuest Dissertations Publishing, 2010. 10437520.

(6) Li, Ying .The research on the molding of Chinese three-dimensional animation roles, Unpublished master thesis, Shanghai University (People's Republic of China), ProQuest Dissertations Publishing,

(7) Ma, Qian .A study on Chinese comic fan's sensation difference about the sino- Japanese animation, unpublished master thesis, Central South University (People's Republic of China), ProQuest Dissertations Publishing, 2010. 10445381.

(8) Sun, jia .research on dougong generation in computer aided automatic generation of Chinese ancient architecture animation, unpublished master thesis(m.a.), Beijing university of technology (people's republic of China), ProQuest Dissertations Publishing, 2009. H216615.
(9) Xue, Fei, The dreamer: An examination of Chinese philosophical concepts and audience through animation, unpublished master thesis (M.F.A), Art and Design Department, Iowa State University, United States, ProQuest Dissertations Publishing, 2016. 10167842.

(10) Yang, Hao, 1981-2010: the communication history of japanese anime in china, Unpublished master thesis, Nankai University (People's Republic of China), ProQuest Dissertations Publishing, 2011. 10487983.

(11) Ye, Hong Pian .A Study on the Type of Character Images in Chinese Animation, unpublished master thesis (M.A.) ,Shanghai University (People's Republic of China), ProQuest Dissertations Publishing, 2007. H317722.

(12) Yuan, Fang .A study of chinese anime industry: based on the inspection of tows, unpublished master thesis, Wuhan University (People's Republic of China), ProQuest Dissertations Publishing, 2010. 10368863.

\section{3-Stand-alone Web document (no date)}

- https://ar.wikipedia.org/wiki/\%D8\%AA\%D8\%A7\%D9\%86\%D 9\%83\%D9\%88\%D8\%A8\%D9\%88\%D9\%86\#cite_note-

\section{4- Stand-alone Web document (no author, no date)}

(1)https://ar.wikipedia.org/w/index.php?title=\&oldid=20395834

(2)http:// WWW.Shanghai Animation Film Studio.COM

(3)http:// www.srimeenakshimobiles.com

(4)https://www.youtube.com/watch? $v=$ cbgAWcTHe-A

(5)http://geo.creativecow.net/ar/th/237/1671/1

\section{5- Journal article from database}

(1)Brown, S.T.Cinema anime: Critical engagements with Japanese animation (2006) Cinema Anime: Critical Engagements with Japanese Animation, pp. 1-248. Cited 10 times.

(2)Bryce, M., Cheung, P., Gutierrez, A.K.Clones, hybrids and organ transplants in Manga and Anime(2010) International Journal of the Humanities, 8 (5), pp. 279-290. Cited 1 time.

(3)Chan, Y.-H., Wong, N.-L., Ng, L.-L. Japanese language students' perception of using anime as a teaching tool (2017) Indonesian Journal of Applied Linguistics, 7 (1), pp. 93-104.

(4)Grigsby, M,Sailormoon: Manga (comics) and anime (cartoon) super heroine meets Barbie: Global entertainment commodity comes to the United States(1998) Journal of Popular Culture , 32 (1), pp. 59-80. Cited 14 times.

(5)Kim, J.-Y.Critique of the new historical landscape of South Korean animation (2006) Animation, 1 (1), pp. 61-81. Cited 10 times. (6)Mihara, R,Involution: a perspective for understanding Japanese animation's domestic business in a global context(2018) Japan Forum, pp. 1-24. Article in Press.

(7)Mikhailova, Y., Torchinov, E.Images at an impasse: Anime and 
manga in contemporary Russia (2008) Japan and Russia: Three centuries of mutual images, pp. 175-191.

(8)Norris, C. Manga, anime and visual art culture (2009) The Cambridge Companion to: Modern Japanese Culture, pp. 236260. Cited 10 times

(9)Hernandez, A.D.H., Hirai, T, The Reception of Japanese Animation and its Determinants in Taiwan, South Korea and China (2015) Animation, 10 (2), pp. 154-169. Cited 2 times.

(10)Horno López, A, The digital age of Japanese anime [La era digital del anime Japonés](2013) Histories Communication Social, 18 (SPEC. ISSUE OCTOB), pp. 687-698.

(11)Papp, Z. Traditional monster imagery in Manga, Anime and Japanese cinema

(2010) Traditional Monster Imagery in Manga, Anime and Japanese Cinema , 244 p. Cited 1 time.

(12)Plumb, A. Japanese religion, mythology, and the supernatural in Anime and Manga (2010) International Journal of the Humanities, 8 (5), pp. 237-246. Cited 1 time.

(13)Swale, A.D, Anime aesthetics: Japanese animation and the "post-cinematic" imagination (2015) Anime Aesthetics: Japanese Animation and the "Post-Cinematic" Imagination, pp. 1-167. Cited 2 times.

(14)Yoon, A.-R. In between the values of the global and the national: The Korean animation industry (2009) Cultural Studies and Cultural Industries in Northeast Asia: What a Difference a Region Makes, pp. 103-115. Cited 5 times.

(15)Redmond, D. Anime and East Asian culture: Neon Genesis Evangeline (2007) Quarterly Review of Film and Video, 24 (2), pp. 183-188.

\section{-Other}

Japanese dictionary 